\title{
Indirect Current Control of a Filtering and Regeneration System used in DC Substations for Urban Traction
}

\author{
By Vlad Suru* \\ Alexandru Bitoleanu \\ Mihaita Linca ${ }^{\dagger}$
}

The aim of this paper is an easier control method for an active filtering and energy recovery system for high power DC traction substations. This system converts the classical dc traction substation, with 6-pulse three-phase bridge rectifier, in an "active substation". The active substation allows both the braking energy recovery to the power grid and the compensation of current harmonics and reactive power of the current absorbed from the power grid. To achieve this goal an indirect current control method had been investigated and implemented both on a virtual system and on a scale experimental model.

Keywords: Active Traction Substations, Indirect Control, Urban DC Traction Substations.

\section{Introduction}

The most urban railway vehicles are driven by electric motors which are supplied by an overhead line using a pantograph or by a third rail. The dc energy is delivered by the traction substations located along the railway line.

The traction substations are powered by a high or medium voltage threephase grid and they contain a transformer and a diode rectifier (6-pulse or 12pulse three-phase bridge rectifier). The output rectifier gives a dc voltage having, mostly, the rated values of $750 \mathrm{~V}$ (tramways and underground railway, including Bucharest), $1500 \mathrm{~V}$ (regional express and Intercity trains) and even $3 \mathrm{kV}$ (South Africa trains) (Warin et al., 2011; Henning et al., 2008; "TICKET TO KYOTO" project, 2011).

The need to reduce the electric energy consumption and increase the efficiency requires two main actions:

1. The filtering of distorted current absorbed by the traction substations, especially those which contain 6-pulse three-phase bridge rectifiers;

2. The energy recovery developed by the vehicle during the braking process.

\footnotetext{
${ }^{*}$ Lecturer, University of Craiova, Romania.

* Professor, University of Craiova, Romania.

${ }^{\dagger}$ Lecturer, University of Craiova, Romania.
} 
The second function is simplified by the train electric motors which can convert the kinetic energy developed by the vehicle in electric energy. Nowadays, just a small part of the resulted electric energy is reused and only for auxiliary services. The remaining energy is simply wasted on the train braking resistances (if not, the braking energy would increase the catenary voltage).

The substation that allows the additional energy recovery to the power grid and the current harmonics and reactive power compensation is called "active substation" (Warin et al., 2011; "TICKET TO KYOTO" project, 2011; EP1985490 A1, 2008). It also allows the dynamic compensation of the voltage fluctuations on the high voltage line and the limitation of voltage drop across the power line for some specific topologies (Wada Hosny, 2013; Shishime, 2012; Ortega et al., 2011a; 2011b). Achieving these functions requires specific structures and control methods, with high complexity (Popescu et al., 2013; Mahanty, 2014; Bitoleanu et al., 2014; Suru et al., 2013; Suru et al., 2014).

In this paper, an easier control method is analyzed, proposed by the authors for a filtering and regeneration system (SISFREG). This system converts a typical dc traction substation, with 6-pulse three-phase bridge rectifier, in an "active substation".

At first, the system structure and the meaning of each block is presented. The system structure description is followed by the control block structure substantiation based on the indirect current control.

Further the paper illustrates the system numeric model and also the performances for the filtering mode, as well as, for the recovery mode. Numerical data corresponds to a traction substation related to Bucharest underground railway system.

The last section emphasizes the experimental results, for filtering mode, obtained by implementing the proposed control method. In this last section, the conclusions, concerning the performances and advantages of the analyzed system, are also drawn.

\section{The Filtering and Regeneration System Structure}

The main element of the regeneration and filtering system is a shunt active power filter (with IGBTs), which is connected between the traction line, through a unidirectional separating circuit, to the primary winding of the traction transformer (Figure 1). The separating circuit is necessary to allow the regeneration mode operation and it is a step up circuit. The separating circuit has three main functions: works as an energy buffer, between the dc line and the active filter, and does not allow high variations of the current, provides the recovery current flow when the traction motors of the vehicle request it and disconnects the active filter from the dc line if the recovery current does not exist. This way the active filter can accomplish its function, i.e. the harmonics and reactive power compensation.

It has a series simple structure and includes an inductance and a diode connected with the cathode toward the active filter. 
This way the recovery current exist naturally when the dc line voltage (Uc) is higher than the voltage across the compensating capacitor of the active filter (UcF). For the indirect current control implementation, it is necessary to measure the ac currents and voltages (after the couple point of the traction transformer) and the voltage across the compensating capacitor).

For the system control section, other quantities can be also necessary: the active filter ac currents and voltages, the traction rectifier ac currents and voltages, and the dc currents and voltages, respectively, and so on.

\section{Indirect Current Control}

The control system of a shunt active filter must contain a current control loop. The current regulator output gives the transistors control sequences (Suru et al., 2014).

Figure 1. The Block Schematic of the Regenerating and Compensating System for DC Traction Substations with Three-phase Bridge Rectifier

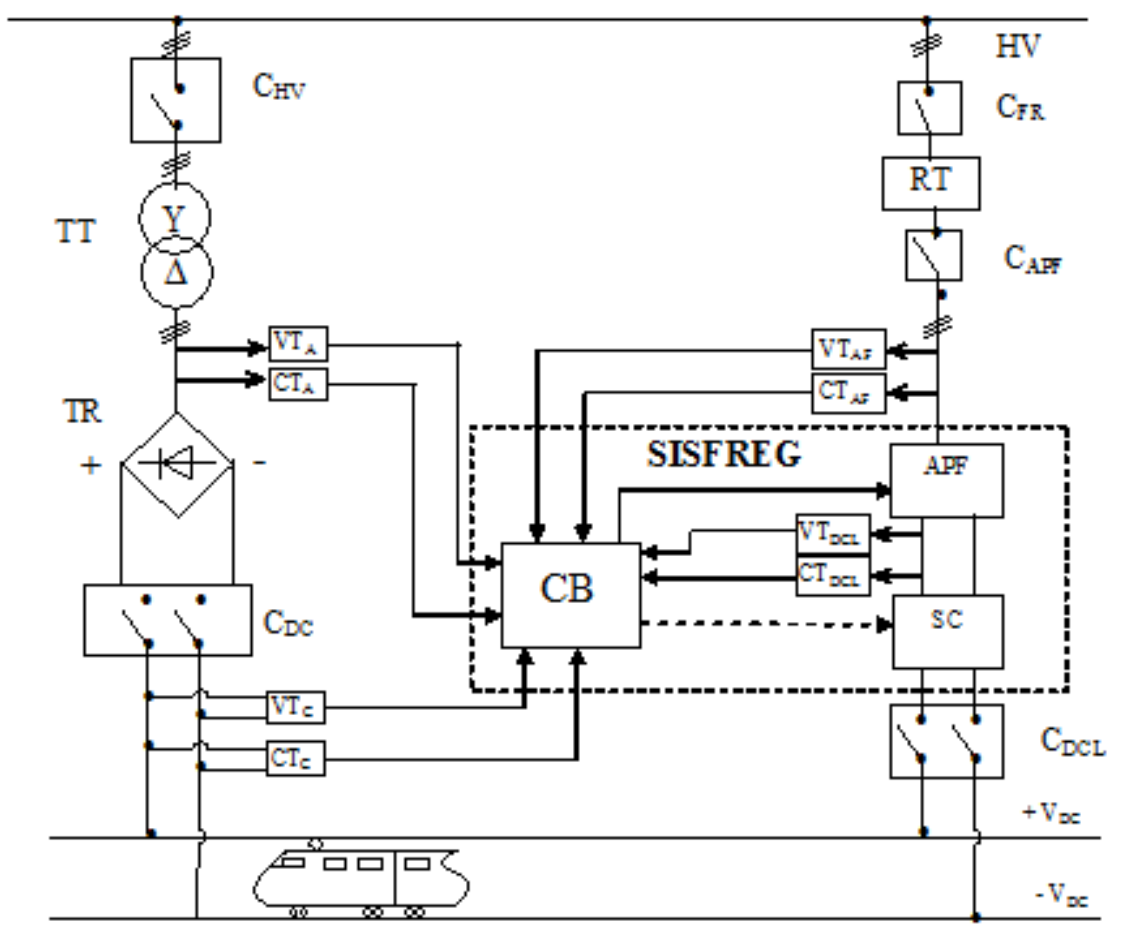

Direct control refers to the active filter output current adjustment and indirect current control involves ac grid current adjustment (Popescu et al., 2013; Mahanty, 2014; Patjoshi and Mahapatra, 2013).

There are two possibilities in order to obtain the desired grid current: based on the distorted load current (pq theory based method, synchronous reference based method, etc.) and based on the dc voltage controller. 
In the regeneration mode, a grid current control loop is necessary. The grid current must be an active current with a distortion enclosed in the standards. Therefore, the most adequate control method is the indirect current control based on dc voltage controller (Tanaka et al., 2009).

To explain the above conclusion, the energy stored in the compensating capacitor is defined as:

$$
E_{C}=\frac{1}{2} C_{d} u_{C}^{2}
$$

obtaining the instantaneous power changed by it,

$$
p_{C}=C_{d} u_{C} \frac{d u_{C}}{d t}
$$

The voltage across the capacitor is expressed as the sum between the continuous component, which is the prescribed value (Ucp) and the alternative component (uc $)$ ) (Figure 2).

$$
u_{C}=U_{C p}+u_{C \sim}
$$

The mean value of the voltage is constant, in steady state, so its derivative is the alternative component derivative. Moreover, approximating:

$$
u_{C}=U_{C p}\left(u_{C \sim} \ll U_{C p}\right)
$$

The instantaneous power becomes,

$$
p_{C} \cong C_{d} U_{C p} \frac{d u_{C \sim}}{d t}=U_{C p} i_{C}
$$

Taking into consideration the typical variation of the voltage across the compensating capacitor of a three-phase shunt active filter, $\mathrm{t}_{\mathrm{m} 0}$ and $\mathrm{t}_{\mathrm{m} 1}$ are the time moments corresponding to two consecutive lowest values, and $t_{M}$ is the time moment corresponding to the highest voltage value (Figure 2).

The meanings of the mentioned periods are:

$\left[\mathrm{t}_{\mathrm{m} 0}, \mathrm{t}_{\mathrm{m} 1}\right]$ - the alternative component period ( $1 / 6$ of the ac grid voltage );

$\left[t_{m 0}, t_{M}\right]-$ the period in which the capacitor receive energy from the power grid;

$\left[\mathrm{t}_{\mathrm{M}}, \mathrm{t}_{\mathrm{m} 1}\right]$ - the period in which the capacitor gives energy to the grid;

The corresponding active powers are obtained as mean values using (5):

$$
P_{d C 1}=\frac{1}{t_{M}-t_{m 0}} C_{d} U_{C p} \int_{t_{m 0}}^{t_{M}} \frac{d u_{C \sim}}{d t} d t=U_{C p} \frac{1}{t_{M}-t_{m 0}} \int_{t_{m 0}}^{t_{M}} i_{C} d t
$$


Figure 2. Voltage on the Compensating Capacitor (ucd) and its Prescribed Value $\left(U_{c p}\right)$

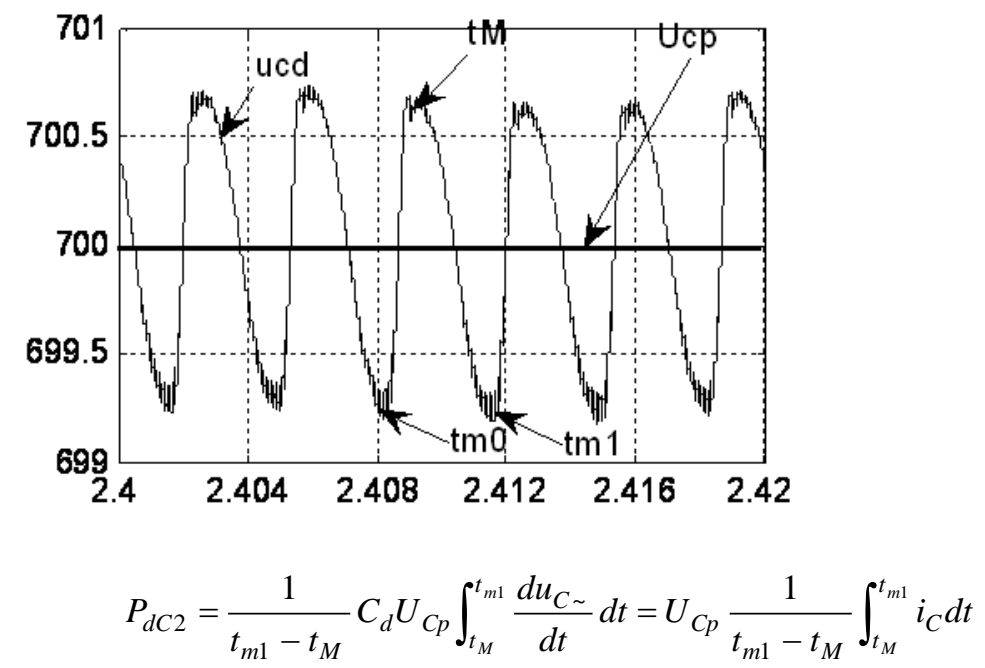

In (6) and (7) the first integrals are equal with opposite sign and represent the voltage oscillation,

$$
\int_{t_{m 0}}^{t_{M}} \frac{d u_{C \sim}}{d t} d t=-\int_{t_{M}}^{t_{m 1}} \frac{d u_{C \sim}}{d t} d t=U_{C \max }-U_{C \min }=\Delta U_{C}
$$

The last two integrals represent the continuous components of the current through the capacitor:

$$
I_{d C 1}=\frac{1}{t_{M}-t_{m 0}} \int_{t_{m 0}}^{t_{M}} i_{C} d t ; I_{d C 2}=\frac{1}{t_{m 1}-t_{M}} \int_{t_{M}}^{t_{m 1}} i_{C} d t
$$
$\mathrm{I}_{\mathrm{dC} 2}$ :

Replacing (8) and (9) in (6) and (7), there can be defined the currents $\mathrm{I}_{\mathrm{dC} 1}$ and

$$
I_{d C 1}=\frac{C_{d}}{t_{M}-t_{m 0}} \Delta U_{C} ; I_{d C 2}=-\frac{C_{d}}{t_{m 1}-t_{M}} \Delta U_{C}
$$

The mean current on the whole period (T/6, the same as for power in a three phase symmetrical system) is the sum between the two currents:

$$
I_{d C}=I_{d C 1}+I_{d C 2}=C_{d} \Delta U_{C}\left(\frac{1}{t_{M}-t_{m 0}}-\frac{1}{t_{m 1}-t_{M}}\right)
$$

Inserting the period and the relative period in which the voltage increases,

$$
t_{m 1}-t_{m 0}=\frac{T}{6} ; x=\frac{t_{M}-t_{m 0}}{T / 6}
$$

The mean current during a period is defined as follow:

$$
I_{d C}=C_{d} \Delta U_{C} \frac{1-2 x}{x(1-x) T / 6}
$$


Figure 3. The Control Structure of the Regenerating and Compensating System for DC Traction Substations with Three-phase Bridge Rectifier

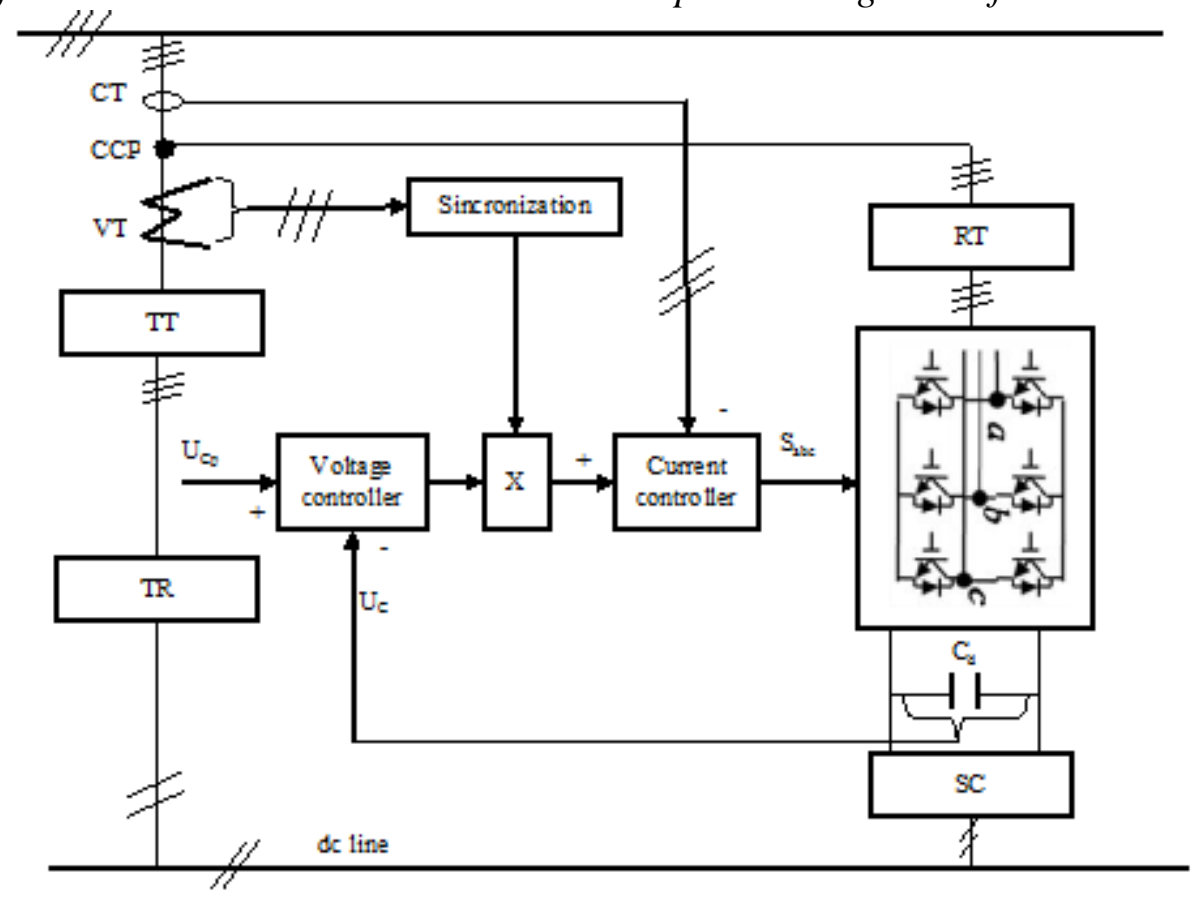

From (13) two important conclusions are drawn:

1. The active current changed by the compensating capacitor to the ac grid is proportional to the voltage oscillation across it. Thus, the voltage oscillation across the capacitor can be used to estimate the active current;

2. The capacitor absorbs active current (active power) if (filtering mode), provides active power if (regeneration mode).

The above conditions describe the filtering and regeneration modes in mathematical terms. So, the regeneration mode operation is obtained only if an external source provides active power to the compensating capacitor, as the dc traction vehicles during the recovery brake process.

Therefore, the control system structure (Figure 3) includes:

- Current transducers (CT) before the couple common point of the traction transformer (TT) and of the regeneration transformer (RT);

- Voltages transducers (VT) for the primary winding of the traction transformer;

- Synchronizing block which gives three sinusoidal signals of unity amplitude and with the same phase as the phase voltages;

- The PI voltage controller;

- The current controller (variable hysteresis band to limit the maximum frequency). 
The voltage controller output, which represents the active current amplitude of the traction transformer- regeneration transformer assembly, is multiplied by the synchronization signals. This way it is obtained the desired current grid. To the current controller output there are obtained the control signals for the voltage inverter transistors.

Passing and operating in the regeneration mode exist naturally, these processes being conditioned by the following aspects:

1. The compensating capacitor voltage control loop, keeps the voltage to the reference value, with deviations not exceeding 5\% (Henning et al., 2008);

2. When $U_{c}>U_{c F}$, the diode is forward biased and allows the existence of the recovery current; the voltage error applied to the voltage controller becomes negative, and the control block prescribes to the active filter an active current with opposite phase to the grid voltage.

\section{The Simulink Model and Numerical Results}

The Simulink model of the system in Figure 3 is illustrated in Figure 4. It can be seen that the model contains all the structural components grouped in Simulink blocks making the model easier to be understood and debugged:

- $\quad$ Three-phase power grid - $20 \mathrm{kV}$ three-phase sinusoidal voltage source;

- The traction transformer and traction rectifier - the 6-pulse diode rectifier with its corresponding transformer and smoothing filter which feeds the catenary;

- Catenary / vehicle - this block implements the dc power line with a train which accelerates or decelerates;

- $\quad$ The active filter containing:

- The adapting transformer

- The interface filter (1st order, inductive)

- The power inverter

- The interface circuit (which includes the interface diode and compensating capacitor);

- The APF control block. 
Figure 4. The Simulink Model of the Regenerating and Compensating System for DC Traction Substations with Three-phase Bridge Rectifier

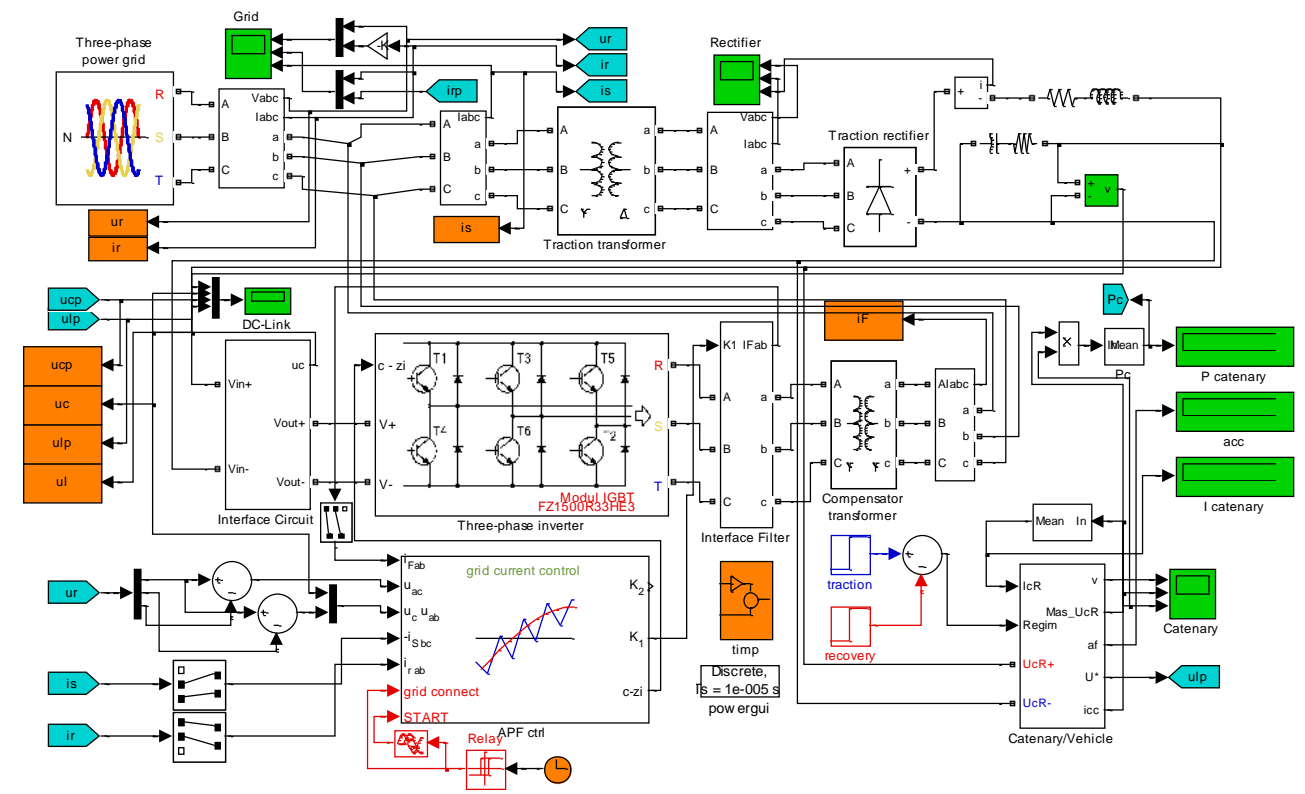

The model can function in two modes:

- Traction / compensation - when the Catenary/Vehicle block acts like the train accelerates. In this case, the three-phase traction rectifier is functional consuming power from the power grid and supplying the catenary. In turn, the active compensator, is in filtering mode, compensating the distortion and reactive power absorbed by the traction rectifier. The grid current is almost sinusoidal in phase with the voltage.

- Braking / recovery - when the Catenary/Vehicle block acts like the train decelerates. In this case, the three-phase traction rectifier is blocked, the voltage on the catenary increases, opening the compensator interface circuit. Now, the power flows from the catenary to the compensating capacitor and further to the power grid via the compensator power inverter and transformer. The grid current is also sinusoidal, but having reversed phase, the power is transferred from the catenary to the power grid.

The operating mode (traction / braking) of the DC line is automatically controlled to simulate the sequence traction - braking - traction. Every transition is validated after the system reaches stationary regime.

The current absorbed by the traction substation, without the active filtering system is illustrated in Figure 5. It is a typical current absorbed by a three-phase thyristor rectifier which uses a $\mathrm{Y}-\Delta$ power transformer. 
Figure 5. The Current Absorbed from the Power Grid by the Traction Substation without Current Compensation

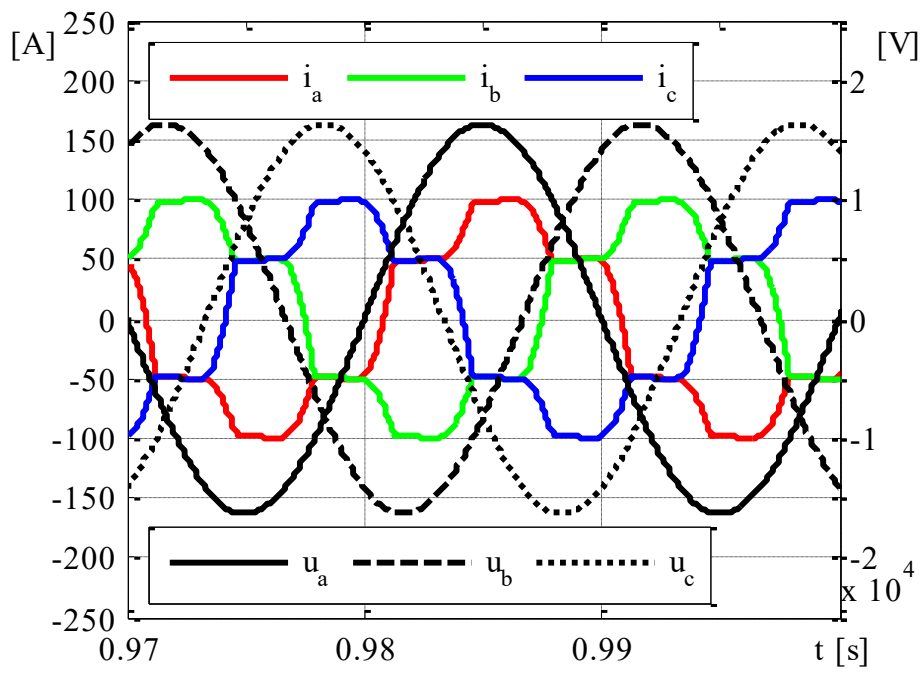

The active power absorbed from the grid is about $2.25 \mathrm{MW}$, close to the nominal power. When the substation uses the active filtering system, the current absorbed from the grid in traction operation is illustrated in Figure 6.

Considering a strong power grid, the voltages on all phases are sinusoidal. The harmonic distortion of the current absorbed by the active substation, on the other hand, is dependent on the active filter performance, the current total harmonic distortion factor being reduced from $21.55 \%$ before the compensation, to $2.71 \%$, after the compensation. This gives a filtering efficiency of 7.95.

Figure 6. The Current Absorbed from the Power Grid by the Active Substation in Traction Operating Mode

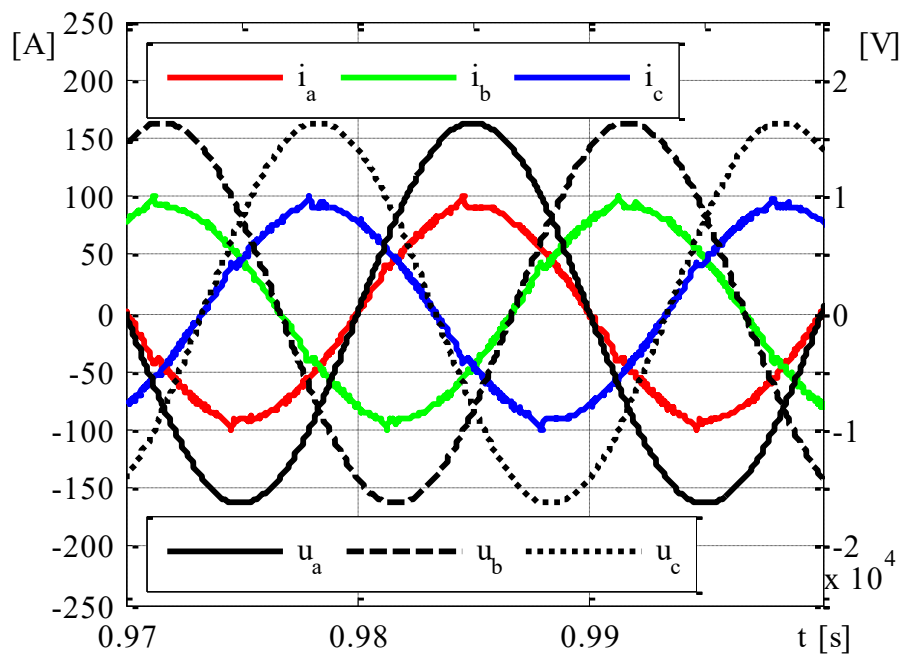

At a given time, the train starts braking so the catenary voltage increases, naturally ceasing the rectifier operation. At the same time the interface diode turns 
on, so the braking energy is transferred to the compensating capacitor, increasing the active filter DC-Link voltage (Figure 7a).

Figure 7. The Transition between the Traction Operating Mode and the Recovery Mode: a) DC-Link and Catenary Voltages, b) Grid Currents and Voltages

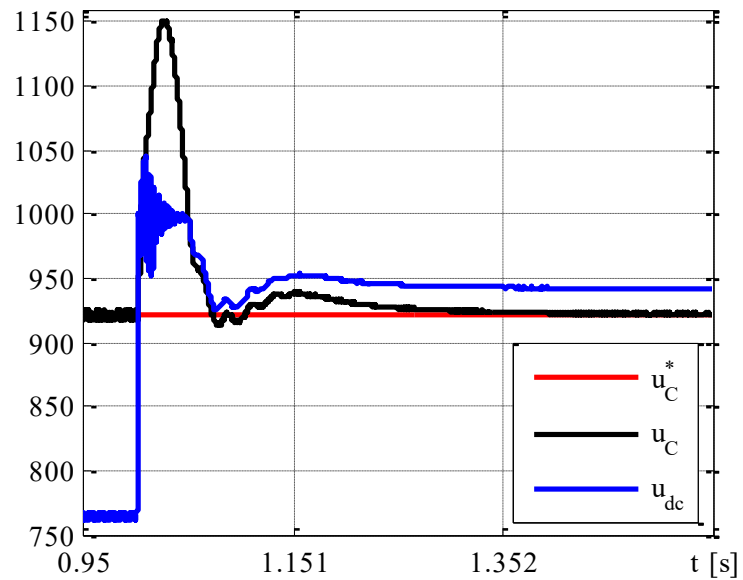

a)

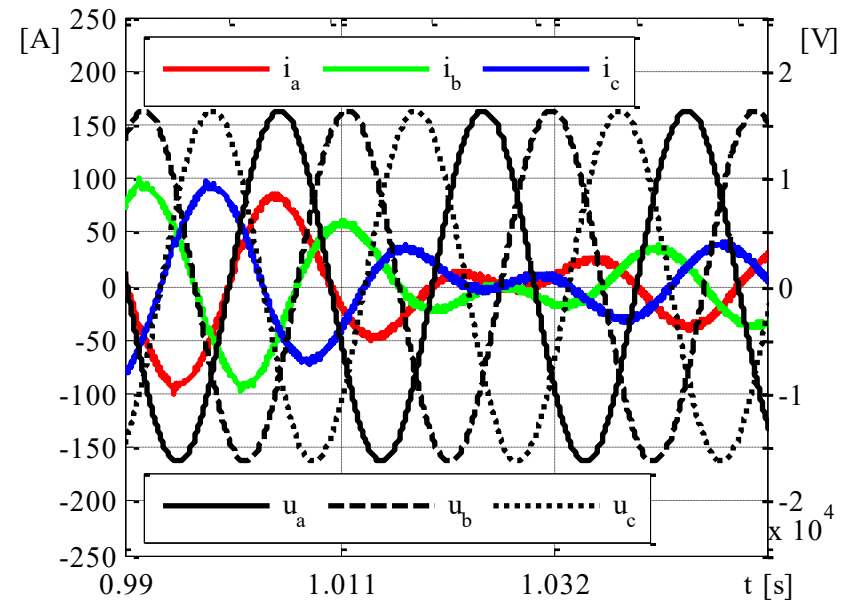

b)

This increase will determine the voltage regulator to prescribe to the filter an active current with opposite phase to the voltage (Figure 7b), the current being greater as the catenary voltage is higher. This way, the braking energy is transferred from the compensating capacitor to the power grid. The transition between the traction mode and the recovery mode is illustrated in Figure $7 \mathrm{a}$ for the DC-Link and catenary voltages and in Figure $7 \mathrm{~b}$, for the grid current.

It can be seen that the system reaches steady state in about $395 \mathrm{~ms}$.

The recovery current waveform in steady state is presented in Figure 8 . The total harmonic distortion of the current generated by the active substation to the power grid is $2.11 \%$. The recovered power is about $1.55 \mathrm{MW}$. 
Figure 8. The Current Injected to the Power Grid by the Active Substation in Energy Recovery Mode

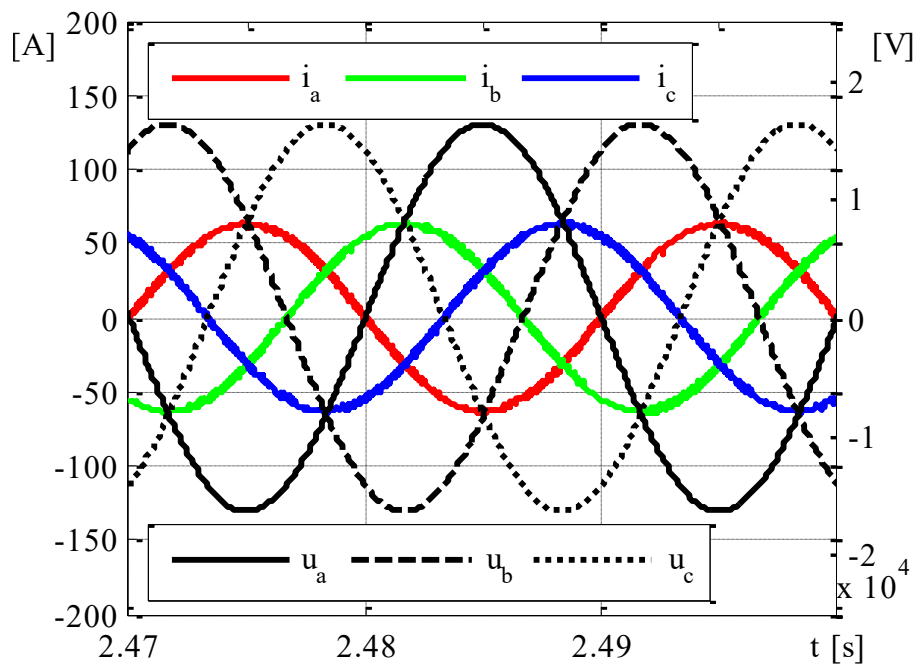

As it results both from the waveforms and the total harmonic distortion values, the recovery current is closer to the sinusoidal wave than the traction filtered current. This is because it is easier for the active filter to generate a sinusoidal current than a complicated waveform compensating current (the more so, the DC-Link voltage being higher in energy recovery mode than in the traction / filtering mode).

Moreover, the compensating current must contain the substation traction rectifier steep current rises due to diode commutations, and for the filter to be able to generate such currents, the DC-Link voltage must be greater as the filtered current di/dt is higher. This condition is less important in energy recovery mode, because the DC-Link voltage increases either way to about $950 \mathrm{~V}$ and at the same time, the generated sinusoidal current di/dt is low, but becomes very important in traction/filtering mode. It results from the higher THD and waveform imperfections (which appear at the commutation moments) that the filter would feel the need for a DC-Link voltage higher than $920 \mathrm{~V}$. However, the voltage is limited by the system requirements.

At another moment of time, the train starts accelerating so the catenary voltage decreases, naturally starting the traction rectifier operation. At the same time the interface diode turns off, so the active filter DC-Link is decoupled from the catenary (Figure 9a). 
Figure 9. The Transition between the Energy Recovery Mode and the Traction / Filtering Mode: a) DC-Link and Catenary Voltages, b) Grid Currents / Voltages

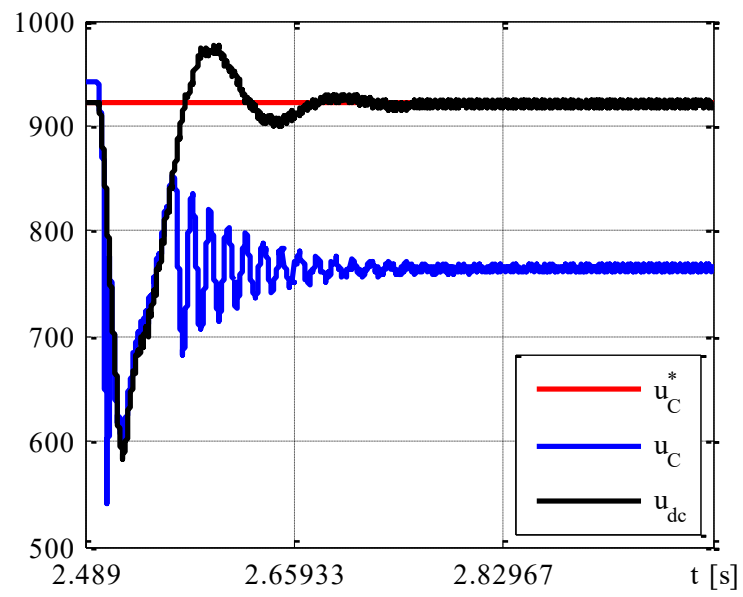

a)

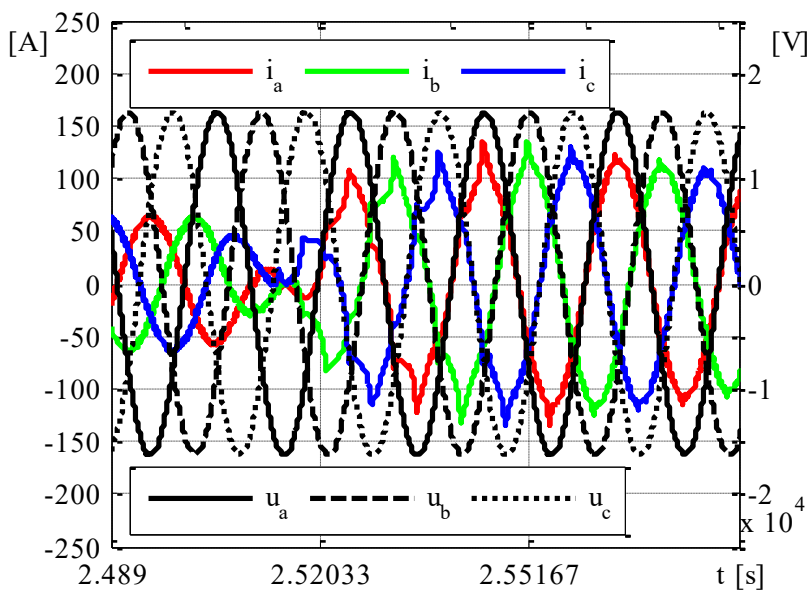

b)

Depending on the voltage regulator response time, the DC-Link voltage continues to drop as the recovery current continues to flow from the DC-Link towards the power grid, discharging the capacitor. This decrease will determine the voltage regulator to prescribe to the filter an active current in phase to the voltage (Figure $9 \mathrm{~b}$ ), to reestablish the prescribed capacitor voltage value of about $925 \mathrm{~V}$ and also, another active current corresponding to the traction rectifier active current component drawn from the power grid. It can be seen that the compensation function of the active filter is intrinsic and cannot be activated or deactivated for this indirect current control method.

The transition time between the recovery functioning mode and the filtering mode is about $288.5 \mathrm{~ms}$. 


\section{Experimental Results}

The results obtained by simulation were experimentally verified using a scale model of the active filtering component of the active substation. Because the scale model does not contain the catenary, but only the active filter and traction rectifier, the energy recovery could not been experimentally verified, but in the filtering mode, the control algorithm of the active filter was completely verified and validated.

For this purpose, a three-phase rectifier was connected to the $380 \mathrm{~V}$ power grid absorbing a current of about $11.5 \mathrm{~A}$ (Figure 10). The grid voltage and current were captured using the Metrix OX 7042-M digital oscilloscope.

Figure 10. The Current Absorbed from the Power Grid by the Traction Rectifier without Current Compensation

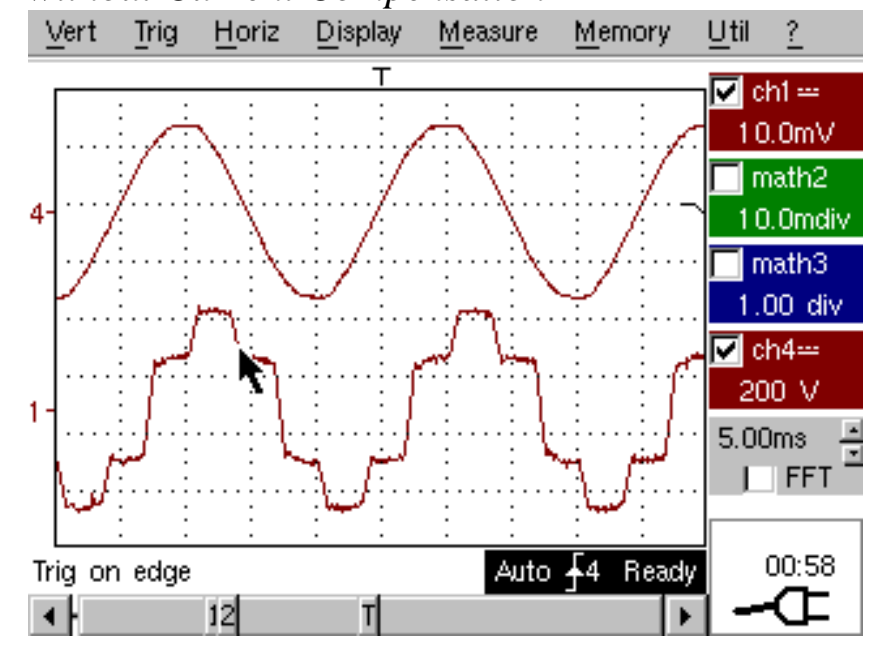

The active filter connected at the PCC has the rated power of $9.5 \mathrm{kVA}$. No adapting transformer was necessary for the compensator, its nominal AC voltage rating being $380 \mathrm{~V}$. The filter main parameters are (Bitoleanu et al., 2014; Suru et al., 2013; Suru et al., 2014):

- $\quad 1^{\text {st }}$ order interface filter $(4.4 \mathrm{mH})$;

- $1100 \mu \mathrm{F}$ DC-Link capacitor;

- 700 V DC-Link prescribed voltage.

The active filter was controlled using a dSpace DS1103 control board. The Simulink model compiled by the board specific software and loaded to the program memory contained the same control block of the active filter in Figure 3. The only change was the replacement of the virtual traction rectifier and virtual active filter power components (interface filter, power inverter and DC-Link capacitor) with the DS1103 Simulink input and output ports (physically connected to the experimental system transducers) (Figure 11).

After the compensation, the current absorbed from the power grid is illustrated in Figure 12. It can be seen that the current waveform is almost 
sinusoidal, excepting for the current ripple which is rather high compared to the load current RMS value. This ripple is partially caused by the interface filter inductances of $4.4 \mathrm{mH}$ (this value was chosen as a compromise between a relative low output current ripple and a fast response time of the active filter).

Also, because the DS1103 time step is limited at its lowest value, the minimum value of $20 \mu$ s for this control program is insufficient to maintain the current hysteresis band, so the current ripple is the more increased.

Figure 11. The Experimental Active Filter Control Simulink Model Compiled and Loaded to the DS1103 Program Memory

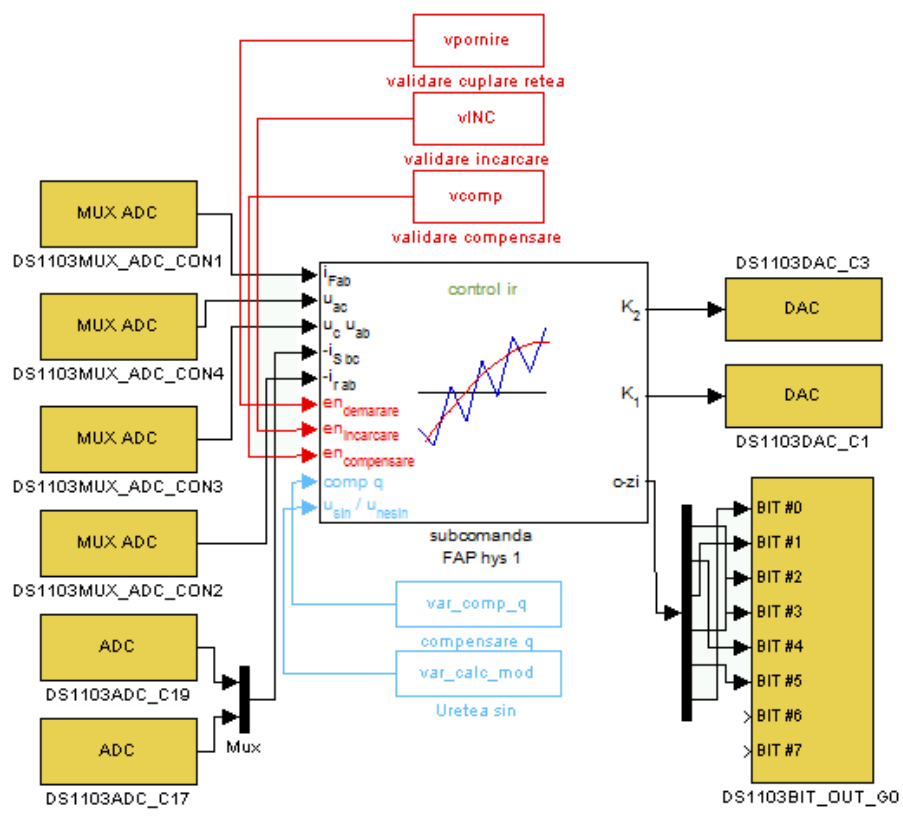

Irrespective of the current ripple which produces high order harmonics, the grid compensated current is also distorted by the active filter control loops response, especially by the voltage regulator, whose output change over a period gives a non-sinusoidal losses covering current, altering the overall grid current. This kind if distortion gives low order harmonics in the grid compensated current. 
Figure 12. The Current Absorbed from the Power Grid by the Traction Rectifier after the Current Compensation

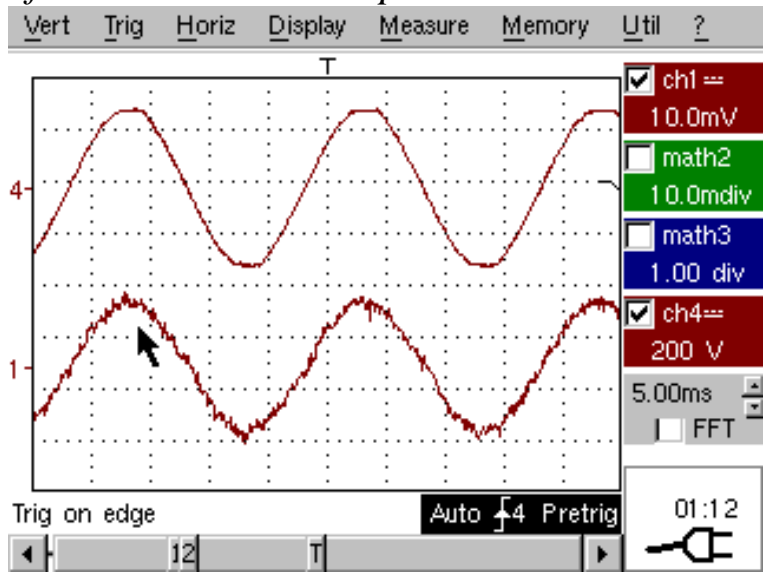

The total harmonic distortion factor of the power grid current was reduced after the compensation from $24.19 \%$ to $8.61 \%$. But, the total harmonic distortion factor includes the high order harmonic produced by the hysteresis current regulator (the switching frequency is between 10 and $12.5 \mathrm{kHz}$ producing harmonics between 200 and 250). More relevant to the compensation method performance is the partial distortion factor, calculated for the first 51 harmonics. Thus, the grid compensated current PHD is $4.22 \%$ which shows that about half of the compensated current harmonic distortion is produced by the active filter switching operation.

On the other hand, these results are influenced by the experimental system relative low power. Considering an industrial system with a current to be compensated ten times greater, for example, for the same hysteresis band (current ripple) the total harmonic distortion factor will be a lot smaller, close to the partial distortion factor (the current fundamental being much greater for about the same current ripple).

\section{Aknowledgments}

This work was performed through the program Partnerships in priority areas PN II, conducted with the financial support of MEN - UEFISCDI, project no. PNII-PT-PCCA-2013-4-0564 (42/01.07.2014).

\section{Conclusions}

The proposed control algorithm of the active filtering and energy recovery system and the virtual models of the system were validated by the obtained results. Also, the results obtained by simulation were experimentally verified using a scale model of the active filtering component of the active substation. Because the experimental scale model does not contain the catenary, but only the active filter and traction rectifier, the energy recovery could not been 
experimentally verified. Although, due to the similitude of the simulation and experimental results, in case of the filtering mode, the proposed algorithm is validated for filtering mode as well as for energy recovery mode.

\section{References}

Bitoleanu, A., Popescu, M., Suru, V. High Performance Shunt Active Power Filter: Design Consideration and Experimental Evaluation, Analele Universitatii Eftimie Murgu Resita Fascicola de Inginerie, ANUL XXI, NR. 3, 2014, ISSN 1453 - 7397, p. 153-166.

EP1985490 A1; 29 Oct 2008: System, substation and method for recovering brake energy from railway vehicles, railway vehicles for this system.

Henning, P.H., Fuchs, H.D., le Roux, A.D., Mouton, H.T. A 1.5-MW Seven-Cell SeriesStacked Converter as an Active Power Filter and Regeneration Converter for a DC Traction Substation, IEEE Trans. on Power Electronics, Vol.23, Issue 5, 2008, pp. 2230 - 2236.

Hosny, W., Park, H.E., Song, J.H. Investigation of Shunt Active Power Filters in Railway Systems, Substation Installation, Journal of Energy and Power Engineering 7 (2013) 1974-1979.

Mahanty, R. Indirect current controlled shunt active power filter for power quality improvement, Electrical Power and Energy Systems Journal, nr. 62/2014, p. 441449.

Ortega, J.M., Ibaiondo, H., Romo, A. Kinetic Energy Recovery on Railway Systems with Feedback to The Grid, World Congress on Railway Research, 22-26 May, 2011a, Lille, France.

Ortega, J.M. Ingeber System for Kinetic Energy Recovery \& Metro Bilbao Experience, Rail Technological Forum for Internationalization, June 2011b, Madrid.

Patjoshi, R.K., Mahapatra, K.K. Performance comparison of direct and indirect current control techniques applied to a sliding mode based shunt active power filter, India Conference (INDICON), 2013 Annual IEEE, ISBN 978-1-4799-2274-1, p. 1-5.

Popescu, M., Bitoleanu, A., Suru, V. A DSP-Based Implementation of the p-q Theory in Active Power Filtering under Nonideal Voltage Conditions, IEEE Transaction on Industrial Informatics, Volume 9, Issue 2 May, 2013, p. 880-889.

Shishime, K., Practical Applications of the Railway Static Power Conditioner (RPC) for Conventional Railways, MEIDEN Review, No. 156, 2012, p. 38-41.

Suru, V., Popescu, M., Patrascu, A. Using dSPACE in the Shunt Static Compensators Control, Annals of The University of Craiova, No 37, 2013, ISSN 1842-4805, p. 9499.

Suru, V., Linca, M., Patrascu, A. Evaluation of current control methods in three-phase shunt active power filters system, Analele Universitatii Eftimie Murgu Resita Fascicola de Inginerie, ANUL XXI, NR. 3, 2014, ISSN 1453 - 7397, p. 177-188.

Tanaka, T., Ishikura, N., Hiraki, E. A Constant DC Voltage Control Based Compensation Method of an Active Power Quality Compensator for Electrified Railways, IEEJ Trans 2009; 4: 435-441.

The "TICKET TO KYOTO" project, Overview of braking energy recovery technologies in the public transport field, March 2011, www.tickettokyoto.eu.

Warin, Y., Lanselle, R., Thiounn, M. Active substation, World Congress on Railway Research, 22-26 May, 2011, Lille, France. 